\title{
Habitat variation at different scales and biotic linkages in lotic systems: consequences for monitorization
}

\author{
Rui Manuel Vitor Cortes · Samantha Jane Hughes • \\ Simone Graça Pinto Varandas • Marco Magalhães • \\ Maria Teresa Ferreira
}

Received: 29 April 2008/ Accepted: 2 January 2009/Published online: 22 January 2009

(C) Springer Science+Business Media B.V. 2009

\begin{abstract}
The Water Framework Directive (WFD) requires the hydromorphological assessment of water bodies, thereby acknowledging the importance of these features in supporting biological quality elements and providing a more complete ecological characterization of surface water bodies. Using a dataset covering mainland Portugal (about 300 sites spread along the different river types) and based on the River Habitat Survey (RHS) field methodology, our aim was to test the spatial variation and the relative role of an array of multi-scale habitat descriptors, in order to: (a) to analyse their geographical variation; (b) to identify the
\end{abstract}

R. M. V. Cortes $(\bowtie)$. S. G. P. Varandas

Forestry Department, CITAB, Centre for Research and

Technology of Agro-Environment and Biological

Sciences, Universidade de Trás-os-Montes e Alto Douro, Apartado 1013, 5001-811 Vila Real, Portugal

e-mail: rcortes@utad.pt

\section{Magalhães}

Forestry Department, Universidade de Trás-os-Montes e Alto Douro, Apartado 1013, 5001-811 Vila Real, Portugal

\section{S. J. Hughes}

Centre for Macaronesian Studies, University of Madeira, Campus da Penteada, 900-390 Funchal, Portugal

\section{T. Ferreira}

Forestry Department, Instituto Superior de Agronomia, Tapada da Ajuda, 1349-017 Lisbon, Portugal principal variables that express human disturbance; and (c) to assess how three different aquatic communities (invertebrates, fish, and macrophytes) were related to those environmental descriptors. We found that hydromorphological variables described by RHS varied significantly over large geographical scales and were more strongly associated with the principal catchments rather than river type (derived from climatic, geological, and typological factors). RHSderived descriptors were of greater importance in assessing disturbance and were closely related to land use and vegetation on the banks and along the river corridor, despite the considerable geographical variation. Habitat variables were more clearly associated with macrophytes and fish than with the benthic macroinvertebrates, a facet of sampling design, since the scale of biological survey for the former two biological groups approaches the scale used to characterize the surrounding environment. An array of environmental variables, ranging from instream features to bankside and river corridor land use features, was associated with each community, making it difficult to discern any common underlying pattern. Based upon our findings, we propose that hydraulic variables should be included in hydromorphological assessment to improve both the performance of physical indicators and the correspondence with the demands of the WFD.

Keywords Biological survey - Spatial scale · River type · Disturbance - Typology 


\section{Introduction}

Contemporary methods for characterizing physical features of the aquatic ecosystems play an important role in river or catchment management, since they include a set of multi-scale descriptors ranging from microhabitat features to large-scale geomorphological processes that aim to establish links over hierarchical spatial scales. For example, Amoros (2001) developed a hierarchical framework for the design of process-orientated restoration projects comprising three nested levels (fluvial sectors, floodplain waterbodies, and mesohabitats). Brierley and Fryirs (2000) developed a physical assessment methodology using hierarchical steps that took entire spatial levels into consideration. Spatial scales considered in these assessment techniques included the catchment type, landscape units, river and reach type, geomorphic units, and hydraulic units.

The identification of regional processes (largescale, e.g., catchment and landscape patterns) that shape local factors (small scale, e.g., reach characteristics and microhabitat) can vary according to the type of organism group under study, necessitating some caution in the use of multi-organism groupbased studies, since target groups may respond differently to the same stressor(s). Several studies have found that global organism richness in each community or distribution patterns were mainly determined by environmental parameters operating at large spatial scales. These scale processes were found to be vital by Stevens and Wilig (2002) in their study on bats, Shurin et al. (2000) on zooplankton gradients, and Heino et al. (2002, 2003) and Hughes et al. (2008) in assessing macroinvertebrate distribution patterns and diversity in high latitude and Mediterranean stream systems. Conversely, several benthic community studies (Tickner et al. 2000; Oliveira and Cortes 2005) have found only a weak association between larger scale descriptors and biological components in comparison with local variables. The absence of close links in these studies was attributed to the presence of riparian ecotones, which can mitigate against disturbance via excess sediment and nutrient retention and modification of energy sources (Naiman 1992; Jaworski 1993; Roth et al. 1996) resulting from perturbation at a regional spatial scale. Authors like Gergel et al. (2002) have even suggested that large-scale variables must be excluded from monitoring programmes because of increasing costs and reduced links with the biota, whereas Frappier (2007) believes that historical land management methods such as large-scale land clearance shape local habitat morphology. These findings present a "never-ending story" of habitat descriptors, spatial scale, and target species selection. The type of community descriptors used in a study, such as taxa distribution or metrics, representing attributes of each community can influence the degree of hierarchical interdependence observed. Even single group studies suffer from inconsistencies in determining biotic links with environmental factors. For example, observed patterns for fish communities can be affected by changes in resource partitioning. Studies on highly interactive fish communities, where biotic processes such as high levels of competition occur, refer to the predominance of local processes (Tonn et al. 1990). However, when biotic interactions decrease, community patterns tend to be determined by regional factors (Oberdoff et al. 1998). An intriguing question concerning these shifts in the prevalence of biotic or abiotic effects is: are they affected by study design factors and/or the geographical area under study? A compilation of studies of factors affecting fish community structure (Jackson et al. 2001) found that the spatial scale of each study determined the outcome. Similar to the studies of Tonn et al. (1990) and Oberdoff et al. (1998), smallscale studies emphasized the importance of competition whereas large-scale studies gave emphasis to abiotic controls. However, this apparent spatial pattern can be a facet of the greater ease with which local-scale factors can be sampled and correlated with fish distribution patterns when compared with large-scale processes (Lamouroux et al. 1999). Moreover, effects of both local and regional processes may interact or they may be biologically expressed in different ways. For instance, fish communities in intermittent Mediterranean streams were found to respond to both spatial scales; however, variability in species richness was attributed to landscape descriptors, whereas variations in abundance were controlled by local variables (Mesquita et al. 2006).

All of these considerations and apparent contradictions demand serious attention when defining an appropriate environmental characterization programme for a determined area, since the selection 
of appropriate scales for habitat characterization and associated metrics to describe biologically relevant responses to stressors are fundamental considerations. Moreover, EU Member States must accommodate the demands of the Water Framework Directive (WFD), which requires the development and implementation of biological monitoring methods for assessing surface water ecological quality. Under the WFD, ecological quality is determined via the assessment of four biological elements (fish, invertebrates, macrophytes, and phytobenthos) and a predefined river typology is required to enable realistic comparison of monitoring sites with reference conditions (conditions found at sites with no or minor impacts). WFD river typology is determined using one of two systems: system A uses a fixed list of variables including ecoregion and categories of environmental descriptors (altitude, size, and geology), while system B provides a more flexible approach, combining obligatory factors (altitude, latitude, longitude, geology, and size) and additional optional physical and chemical factors related to environmental conditions.

Biological data are not used exclusively in defining ecological status; under the WFD, "high" ecological status is established using both biological components, hydromorphological features and physicochemical water quality. This requires a fundamental understanding of the links between environmental condition and biota (Logan and Furse 2002) in order to develop targets that will result in surface water bodies attaining "good" ecological status under the normative definitions of the WFD.

This study, carried out using data of ecological conditions across the entire mainland Portuguese territory, illustrates our attempt to assess the feasibility or limitations of ecological status as defined by the WFD by: (1) attempting to identify simple and complex habitat descriptors, expressed at two local spatial levels (instream habitats and the river corridor), which exhibit sensitivity to a range of anthropogenic stressors; (2) comparing the geographical variation of the physical parameters that define the diversity of assessment procedures (i.e., habitat parameters) between the WFD's artificially created river type boundaries and the natural division of the catchment borders; (3) establishing associations between three aquatic organism groups (macroinvertebrates, fish, and macrophytes) and environmental descriptors, as well as their spatial variation along the same discrete boundaries of river type and catchment. From our findings, we will present suggestions for improving habitat characterization techniques to better accommodate WFD requirements such as inclusion of multiscale variables and hydromorphological elements describing hydrological regime, river continuity, and morphological conditions during field observations.

\section{Methods}

\section{Field survey}

Stream networks (order 2-7) from a total of 16 catchments, ranging from the River Minho in the North to the Guadiana in the South were sampled across the country in spring 2004 and 2005. Sampling during the first year was carried out under extraordinarily low-flow conditions, a consequence of an exceptionally dry year (the lowest recorded rainfall levels in 60 years).

A total of 299 sites were sampled, of which almost half represented reference or less disturbed conditions. Sites were selected by applying criteria used to assess the degree of human impact on European rivers (FAME Consortium 2004), linked to the implementation of the WFD and based on the principles of REFCOND (2003). Sites were classified according to their position along the disturbance gradient by quantifying 10 stressors that included: land use intensification (the presence of continuous agricultural activities), urban area, riparian layer structure (including invasive plants), river connectivity, sediment load, hydrological modifications (water abstraction and flow regulation), symptoms of acidification or toxicity, morphological condition (disturbance of the physical habitat), symptoms of eutrophication, and invasive plant or animal species. Each variable was allocated to one of five classes according to the magnitude of the stressor under assessment (river connectivity, land use and urban area were estimated by geographical information system for the entire catchment upstream of the selected sites, whereas the other descriptors were assessed in situ and describe only local conditions). Reference sites were defined: (1) according to their total score, derived from ranking the scores of environmental degradation and (2) when none of the above variables occurred in the two "worst" classes. Therefore, reference sites should be considered as "relatively 
less impacted" and should be not assimilated directly to the reference condition like it is defined by the WFD.

Aquatic communities were sampled using semiquantitative procedures adapted from previous versions of the CEN/TC 230 "Water Analysis". Sampling procedures are described shortly here. Benthic fauna was collected by kick sampling along $6 \times 1 \mathrm{~m}$ long transects distributed in proportion to the number of different habitats present at the sampling site. Each sample was collected with a hand-net $(0.50 \mathrm{~mm}$ mesh size) and was immediately sorted at the laboratory. Organisms were preserved in $70 \%$ ethanol and identified to family level. Depending on river depth, fish were captured in a single pass with either a backpack electrofisher or a boat using a CPUE approach and including all habitat types (total distance surveyed: $20 \times$ mean river width, maximum length of $150 \mathrm{~m}$ ). Captured fish were placed in containers, identified to species level, counted, and subsequently released. Macrophytes were sampled wading upstream in zig zag pattern along a $100 \mathrm{~m}$ transect of river channel and river banks. A careful search was made along the transect in order to score recorded taxa on a five-level scale according to their relative cover area. When necessary, plants (in particular bryophytes) were transported in absorbent paper or a plant press to the laboratory for identification. Wherever possible, taxa were identified to species level.

Habitats were assessed at the same time as biological sampling using the River Habitat Survey (RHS; Raven et al. 1997, 1998), a standardized method that collates observational data of instream habitat features and river corridor over a $500 \mathrm{~m}$ reach with a $50 \mathrm{~m}$ buffer on each bankside. RHS methodology comprises two distinct types of observation: (a) 10 transects or "spot-checks" at $50 \mathrm{~m}$ intervals along the $500 \mathrm{~m}$ reach and (b) continuous counts and observations made along the entire $500 \mathrm{~m}$ reach, known as a "sweep-up". Spot-check observations include channel substrate type, flow type, habitat features, aquatic vegetation types, bank vegetation structure, and artificial modifications. The "sweepup" procedure records physical features and modifications not included at the spot-checks, such as land use, riparian stand complexity, channel features, and the extent of artificial features including weirs, bank protection structures, and water abstraction along the channel. Morphometric measurements are recorded at a representative cross-section of the $500 \mathrm{~m}$ reach.
RHS data may be used to derive habitat indices that describe the degree of diversity of natural features (habitat quality assessment) and the extent of artificial features (habitat modification score). Habitat comparisons should be made between sites sharing the same typology. Developed for England and Wales, RHS sites are compared with reference ones identified over natural gradients defined by principal components analysis. Slight modifications were introduced by including target taxa and types of human modifications typically found in Portuguese river systems.

For a more complete characterization of each site, we also made basic hydraulic and geomorphic assessment of instream features, not contemplated by RHS methodology, once they could potentially provide additional information to express anthropogenic impacts or aquatic community distribution patterns. Maximum, average, and minimum of depth and current velocity were recorded at each RHS spotcheck, the number of pools and riffles and riffles/ pools were recorded along the sweep-up, and Froude number, Reynolds number, and shear stress were taken in the cross-section used for morphometric measurements.

\section{Data treatment}

River Habitat Survey is descriptive in character; therefore, it was necessary to group and transform similar types of descriptors, in order to produce new descriptors derived from combinations of original variables (Table 1), allowing more adequate statistical treatment and reducing the number of zero values present in the original dataset of habitat parameters. Derived variables were distributed in two classes: (a) descriptors of instream condition and (b) descriptors of the river corridor.

River typology was defined using system B of the WFD (INAG 2008), namely by applying obligatory factors (geology, altitude, catchment area, latitude, longitude) and a subset of optional factors (average slope, average rainfall, rainfall coefficient of variation, runoff, average temperature, and annual temperature range). System B was applied over several stages: (1) multivariate statistical techniques were used to identify the morphoclimatic regions, which were (2) then crossed with data on geology and catchment area, and then (3) validated biologically by comparing the derived abiotic zonation with the one 
Table 1 Grouping of similar RHS habitat variables used in the analyses with a description of transformation criteria for the RHS original variables

Number of riffles, pools and bars (A) sweep-up

ENR_number of riffles

ENP—number of pools

EPSB $-\sum$ of variables: number of unvegetated point bars, number of vegetated point bars, number of unvegetated side bars, number of vegetated side bars

Artificial features (A) sweep-up

$\mathrm{FAF}-\sum$ of variables: weirs/sluices, culverts, bridges, outfalls/intakes, fords, deflectors/groynes/croys

Physical attributes $(A)$ spot checks

Bank material (dominant-G1BMD, mean-G1BMM, and standard deviation-G1BMSD)

G1BMAS - artificial bank material $\sum$ of variables: concrete, sheet piling, wood piling, gabion, brick/laid stone, rip-rap, tipped debris, fabric, bio-engineering materials

G1BM $-\sum$ of variables: resectioned (reprofiled), reinforced, poached (bare), artificial berm, embanked channel substrate (dominant-G1CSD, mean-G1CSM, and standard deviation-G1CSSD)

G1FT $-\sum$ of variables: free fall, chute, broken standing waves (white water), unbroken standing waves, chaotic flow, rippled, upwelling, smooth, no perceptible flow, dry (no flow)

G1CM $-\sum$ of variables: resectioned, reinforced, culverted, $\mathrm{dam} /$ weir/sluice, ford (man-made)

G1GE $-\sum$ of variables: exposed bedrock, exposed boulders, vegetated rock channel features:

G1MBFNB-marginal and bank features: $\sum$ of eroding cliff and stable cliff

G1CFBR - number of sub-channels for braided river

G1MBFC - marginal and bank features: number of natural berms

G1CSAR_channel substrate: (number of artificial)

G1CFMI-channel features: number of mature islands

G1CFTR - channel features: number of trash (urban debris)

Banktop land use and vegetation structure $(B)$ spot checks

G2For- $\sum$ of variables: broadleaf/mixed woodland (seminatural), Broadleaf/mixed plantation, coniferous woodland (semi-natural), coniferous plantation

G2LUSH—scrub and shrubs

G2LUOR - orchard

G2LUMH-moorland/heath
Land use within $50 \mathrm{~m}$ of banktop $(B)$ sweep-up

H1For $-\sum$ of variables: broadleaf/mixed woodland (seminatural), broadleaf/mixed plantation, coniferous woodland (semi-natural), coniferous plantation

H1LUSH-scrub and shrubs

H1LUOR—orchard

H1LUMN—moorland/heath

H1LUEU-eucalyptus stand

H1LUMO-Mediterranean oak forest

H1Grass $-\sum$ of variables: rough unimproved grassland/pasture, improved/semi-improved grassland, tall herb/rank vegetation

H1LURD—rock, scree or and dunes

H1LUSU—suburban/urban development

H1Agric $-\sum$ of variables: tilled land, irrigated land parkland or gardens

Riparian layer (B) sweep-up

H2MRVW-mean riparian vegetation width

Bank profiles (A) sweep-up

IBPVS $-\sum$ of variables: vertical/undercut, vertical with toe, steep $\left(>45^{\circ}\right)$

IBPG—bank profiles gentle

IABF $-\sum$ of variables: resectioned (reprofiled), reinforcedwhole, reinforced-top only, reinforced-toe only, artificial twostag, poached bank, embanked, set-back embankment

IBPNB - natural berm

Extent of trees and associated features $(B)$ sweep-up

JTREES-trees

JShading $-\sum$ of variables: shading of channel, overhanging boughs

JShelter $-\sum$ of variables: exposed bankside roots, underwater tree roots, fallen trees, large woody debris

Extent of channel and bank features $(A)$ spot checks

KEFT $-\sum$ of variables: free fall flow, chute flow, broken standing waves, unbroken standing waves, rippled flow, upwelling, smooth flow, no perceptible flow, dry, marginal dead water 
Table 1 continued

G2Grass $-\sum$ of variables: rough unimproved grassland/ pasture, improved/semi-improved grassland, all herb/ rank vegetation

G2LURD—rock, scree or/and dunes

G2LUSU—suburban/urban development

G2Agric $-\sum$ of variables: tilled land, irrigated land, parkland or gardens

$\mathrm{G} 2 \mathrm{VB}-\sum$ of variables: banktop and bankface bare vegetation structure

G2VU $-\sum$ of variables: banktop and bankface uniform vegetation structure

G2VS $-\sum$ of variables: banktop and bankface simple vegetation structure

$\mathrm{G} 2 \mathrm{VC}-\sum$ of variables: banktop and bankface complex vegetation structure

$\mathrm{G} 2 \mathrm{MO}-\sum$ Mediterranean oak forest

G2EU- $\sum$ eucalyptus stand

Channel vegetation types $(A)$ spot checks

G3Emerg — emergent reeds sedges rushes grasses and horsetails

G3Hyd $-\sum$ of variables: liverworts/mosses/lichens, emergent broad-leaved herbs, free-floating, amphibious submerged broad-leaved, submerged linear-leaved, submerged fine-leaved

G3Alg-filamentous algae
KEC_- eroding cliff

KEGE $-\sum$ of variables: exposed bedrock, exposed boulders, vegetated bedrock/boulders

$\mathrm{KMCB}-\sum$ of variables: unvegetated mid-channel bars, unvegetated mid-channel bars

KMI-mature island

Features of special interest (A) sweep-up

MMC $-\sum$ of variables: braided channel, side channel(s)

MWC $-\sum$ of variables: nat. waterfall(s) $>5 \mathrm{~m}$ high, nat. waterfall(s) $<5 \mathrm{~m}$ high, nat. cascade(s)

$\mathrm{MB}-\sum$ of variables: very large boulders $(>1 \mathrm{~m})$, Floodplain boulder deposits

$\mathrm{MD}-\sum$ of variables: debris dam(s), leafy debris

Channel dimensions $(A)$ uniform section

LLP - the ratio between the variables water width (m) and water depth $(\mathrm{m})$

LBH-mean banktop height (both banks)

LCBW_-bankfull width

Notable nuisance plant species $(B)$ sweep-up

OIR $-\sum$ of variables: Acacia Ailanthus altissima Arundo donax

Symbols are derived from group designations defined in the original RHS fieldsheet

Variables relate to either (A) instream condition or (B) the river corridor

produced by the multivariate analysis of the WFD organism groups.

A total of 15 river types were derived, although this study contemplates only nine of them (central littoral systems, northern headstreams, northern streams, large basins from Douro catchment, small basins from Douro catchment, North South transition systems, low-altitude southern streams, higher altitude southern streams, and lower areas of Tagus and Sado catchments). Types specific to large regulated rivers (the Douro, the Tagus, and the Guadiana) or specifically associated with peculiar geological layers were excluded (sedimentary rocks of biogenic origin or calcareous sandstone observed in specific regions). Spatial patterns of the habitats were analysed for the nine derived types and also along the spatial partition at catchment level. For this case, several sites located along the central western and southern coast in very small basins were allocated into two different groups to test for the mentioned catchment discrimination.

Stepwise multiple discriminant function analysis (MDA) was used to classify all sites (299) according to river type and catchment, using the RHS transformed variables. This test was complemented with permutational MANOVAs, conducted under a reduced model in order to test for the significance of the variation partitioning of either physical (transformed RHS variables) or biological variables (each community, where taxa were expressed as relative abundance) according to (1) river type, (2) catchment, and (3) reference condition. The latter factor, used to distinguish between disturbed and reference sites (with random variation), was nested with river type and catchment (fixed factors). Only sites with complete datasets (information on all communities and morphological descriptors) were considered for these analyses 
(217 sites) to ensure statistical robustness. Data were transformed prior to analyses: RHS grouped variables were standardized and biological data were $\log (x+1)$ transformed. MANOVAS incorporated two dissimilarity measures, Euclidian distance for RHS and BrayCurtis for biological data. Total abundance values were used for each organism group (total abundance for invertebrates, abundance expressed in number $\mathrm{m}^{-2}$ for fish, and degree of cover for macrophytes).

A forward stepwise multiple regression between the sum of all the human impacts occurring at a site using the 10 parameters from FAME criteria (dependent variable) and transformed RHS descriptors, together with the hydraulic variables (independent, explanatory variables), was conducted in order to select variables $(P<0.05)$ that best responded to environmental degradation. The response of habitat descriptors to disturbance along the geographical gradient was assessed using separate forward stepwise multiple regression procedures for each river type and the global dataset (national dataset).

Canonical correspondence analyses (CCA) were performed using non-intercorrelated RHS variables (assessed by variance inflation factor or VIF values; variables with VIFs $>20$ were excluded) and organism group data to assess the match of each set of biological data with the habitat descriptors. CCA produces ordinations of the taxa to detect their distribution patterns, but the ordination axes are constrained by the predictor variables (environment). The species-environment correlation, calculated as the ratio of the eigenvalue for a particular axis and the amount of community variation represented by the environmental variables, requires careful interpretation since it increases in proportion with the number of environmental variables relative to the number of samples (McCune and Grace 2002). In this study, the proportion remained constant in the CCAs, allowing valid relative comparisons.

A partial canonical correspondence analysis (pCCA) was carried out to assess the relative importance of the two different scales of environmental descriptors for each community, namely instream conditions (from RHS spot-checks) and river corridor (from RHS sweepup). The variables used to describe these two scales are presented in Table 1. For each organism group, (a) a CCA was carried out for the group of the spot-check variables; (b) a CCA was carried out for the sweep-up variables; (c) a pCCA was performed for the spot-checks variables excluding the effect sweep-up variables; and (d) a pCCA was performed for the sweep-up variables excluding the effect of spot-check variables. The separated components of variation were expressed as percentage of the total variation in the species data, derived by dividing the canonical eigenvalues of a specific CCA or pCCA by the total inertia (total variation) obtained by the sum of all the eigenvalues (see Hughes et al. 2008). The significance of the axes was tested by Monte Carlo permutation test. These analyses were carried out on a smaller set of sites (199) since sites where fish were not captured were eliminated. This allowed comparisons of patterns of agreement for each organism group with the environmental data. Multivariate analyses were carried out using the packages STATISTICA v7.0 (Statsoft 2004), CANOCO v4.5 (ter Braak and Smilauer 2002), and PERMANOVA for PRIMER (Anderson and Gorley 2007).

Finally, a multivariate multiple regression, based on a dissimilarity measure (Bray-Curtis; DistLM), was used on all sites in order to derive a linear fit between biological and environmental datasets and thereby determine the principal habitat variables responsible for the composition and structure of each community. The criterion AIC, based on likelihood theory, was used to select the group of environmental variables that increased the amount of explained variation.

\section{Results}

Stepwise multiple discriminant function analysis results displayed greater partition among the main catchments (16 groups; $87.38 \%$ of sites correctly distributed among the defined groups) than among river types (nine groups; those with few cases were discarded; $74.13 \%$ correctly classified among river types), although discrimination was significant in both cases $(P<0.01)$.

MANOVA results (Table 2) show that catchment indicated significant $(P<0.05)$ differences for RHSderived habitat variables and macrophytes and fish and nearly significant for invertebrates, whereas river type produced significant differences for fish communities and RHS data only. Invertebrates and macrophyte groups exhibited significant changes in relation to the level of disturbance $(P<0.01$, nested reference or non-reference conditions).

Forward stepwise linear multiple regression performed to select the environmental variables (RHS 
Table 2 Permutational MANOVA results to test the significance between "river type", "catchment", and "reference conditions"

\begin{tabular}{|c|c|c|c|c|c|c|c|c|c|}
\hline & \multirow[t]{2}{*}{ Levels } & \multicolumn{2}{|l|}{ RHS } & \multicolumn{2}{|c|}{ Invertebrates } & \multicolumn{2}{|c|}{ Macrophytes } & \multicolumn{2}{|l|}{ Fish } \\
\hline & & $P$ & $\%$ & $P$ & $\%$ & $P$ & $\%$ & $P$ & $\%$ \\
\hline River type & 9 & 0.037 & 9.66 & 0.289 & 6.94 & 0.250 & 6.94 & 0.001 & 18.02 \\
\hline Catchment & 15 & 0.003 & 17.00 & 0.052 & 13.80 & 0.013 & 13.53 & 0.001 & 29.94 \\
\hline Type $\times$ catchment & 2 & 0.152 & 12.15 & 0.980 & 0.00 & 0.485 & 0.00 & 0.878 & 0.00 \\
\hline Reference (type $\times$ catchment) & & 0.141 & 9.03 & 0.001 & 21.15 & 0.001 & 16.19 & 0.876 & 0.00 \\
\hline
\end{tabular}

The number of levels, $P$ values, and the percentage of variance explained by each component of variance are listed

Table 3 RHS grouped variables and hydraulic variables added to the model of stepwise multiple regression $(P<0.05)$

\begin{tabular}{lcccl}
\hline Variables & Step & Adjusted $R^{2}$ & $F(30.284)$ & $P$ \\
\hline G1BM & 1 & 0.177964 & 77.50407 & 0.000000 \\
H1LUSH & 2 & 0.065137 & 30.72237 & 0.000000 \\
JTREES & 3 & 0.038315 & 18.98204 & 0.000017 \\
G2LUSU & 4 & 0.031460 & 16.25387 & 0.000068 \\
KEGE & 5 & 0.024058 & 12.84395 & 0.000386 \\
OIR & 6 & 0.026969 & 14.96637 & 0.000130 \\
G2VU & 7 & 0.031035 & 18.05501 & 0.000028 \\
G3Emerg & 8 & 0.025244 & 15.28169 & 0.000111 \\
MD & 9 & 0.011942 & 7.35992 & 0.006999 \\
G2LUOR & 10 & 0.010301 & 6.44750 & 0.011544 \\
MWC & 11 & 0.008658 & 5.48912 & 0.019698 \\
IBPVS & 12 & 0.006943 & 4.44546 & 0.035711 \\
G2LUMH & 13 & 0.006677 & 4.31555 & 0.038503 \\
$V$ (max-min) & 14 & 0.006239 & 3.73643 & 0.049882 \\
Froude no. & 15 & 0.008094 & 4.91130 & 0.027437
\end{tabular}

The dependent variable expresses disturbance level based upon FAME criteria described in the "Methods"

Variables included within each abbreviated group are given in Table 1

and hydraulic ones) that best reflect environmental degradation (Table 3) retained 13 RHS-derived variables and only two hydraulic variables from the initial set of 80 habitat and hydraulic descriptors (variables entered successively in the model if $P<0.05)$. RHS descriptors of greater importance were closely related to banktop and the river corridor land use and vegetation. Interestingly, retained variables were derived from a number of groups of variables covering a wide range of environmental conditions. The same statistical procedure was also applied to each river type (excluding the hydraulic variables); the summary of the results of all selected variables for each case is given in Table 4.
Results clearly show the disparity of RHS parameters associated with the disturbance gradient within each river type, illustrated by the wide range of variables in each group. The higher relative contribution of instream features (e.g., substrate, channel modifications, etc.) was discernible as well as descriptors of land use. Immediate bankside vegetation composition and structure (G1 variables) were more closely associated with the disturbance gradient than river corridor vegetation composition and structure (within $50 \mathrm{~m}$ of the banktop $=\mathrm{H} 1$ variables).

Computed CCA ordinations (Table 5) were all significant $(P<0.05$; Monte Carlo permutation tests for the first axes). Explained variance and correlations between the environment (RHS variables) and the taxa for each organism group suggest that the association between each community and the RHS parameters is successively higher for invertebrates, fish, and macrophytes, respectively.

Although the CCA's indicated the most relevant individual variables that explained the composition of each organism group, partial CCAs (five runs) between the RHS and each community (Fig. 1) identified the relative importance of the instream variables (spot-check data) and river corridor variables (sweep-up data) to each organism group. Results confirm that macrophytes, followed by fish showed a stronger association with environmental data. Both instream and river corridor RHS variables explained similar amounts of variation, with a slightly greater contribution from the latter group of parameters and a lower proportion of shared variance.

DistLM analyses incorporated predictor variables (RHS descriptors and two hydraulic variables selected by the multiple regression), which resulted in smaller AIC values (the criterion used to select the predictor variables that increased the amount of explained variation). The selected variables displayed moderate 
Table 4 Variables selected for each river type by multiple regression compared with variables included in the model for the whole country for $P<0.05$ (hydraulic variables excluded)

\begin{tabular}{|c|c|c|c|c|c|c|c|c|c|}
\hline \multicolumn{9}{|l|}{ River type } & \multirow[t]{2}{*}{ Country } \\
\hline $\mathrm{L}$ & M & N1 & N2 & N3 & N4 & $\mathrm{S} 1$ & $\mathrm{~S} 2$ & S3 & \\
\hline G1BM & G1BMAS & ENR & G2VU & ENP & G1BM & FAF & G1BMAS & EPSB & G1BM \\
\hline G3Emerg & G1CSD & G3Emerg & G1BMSD & FAF & G1CSSD & G2VB & G1BMSD & G1BM & G2LUMH \\
\hline \multirow[t]{14}{*}{ H1LUEU } & G2Grass & H1LUSH & G2Grass & G1BMSD & G3Emerg & G2VS & G1BMM & G1CSM & G2LUOR \\
\hline & G2Agric & H1LUOR & G2LUOR & G1CSSD & G3Hyd & H1LUOR & G2For & H1Agric & G2LUSU \\
\hline & G2For & H1LUSH & G2LUSH & G1CSM & JShelter & H1LUSU & G2LUSH & IBPVS & G2VU \\
\hline & G2LUSH & H1LUSU & $\mathrm{G} 2 \mathrm{VC}$ & G1FT & LCBW & MD & G2VB & JShelter & G3Emerg \\
\hline & G2LUSU & IABF & G3Emerg & G2LUOR & & & G2VC & JTREES & H1LUSH \\
\hline & G2VB & IBPVS & G3Hyd & G2VS & & & JShading & OIR & IBPVS \\
\hline & G2VU & JShelter & H1LUEU & H1LUSH & & & JTREES & & JTREES \\
\hline & H1LUSH & JTREES & IBPVS & JShading & & & $\mathrm{LBH}$ & & KEGE \\
\hline & JShelter & KEGE & JShelter & JTREES & & & & & MD \\
\hline & JShading & & KMI & $\mathrm{LBH}$ & & & & & MWC \\
\hline & JTREES & & LBH & MWC & & & & & OIR \\
\hline & KEFT & & $\mathrm{MB}$ & & & & & & \\
\hline & $\mathrm{MB}$ & & OIR & & & & & & \\
\hline & MWC & & & & & & & & \\
\hline
\end{tabular}

Variables included within each abbreviated group are given in Table 1

The river types are L, central littoral; M, northern headstreams; N1, northern streams; N2, large basins from Douro catchment; N3, small basins from Douro catchment; N4, transition between North and South; S1, southern streams of low altitude; S2, southern streams of higher altitude de; S3, lower areas of Tagus and Sado catchments

Table 5 Results of CCA ordinations between RHS variables and each aquatic community in order to assess the relative performance to match environmental and biological data

\begin{tabular}{|c|c|c|c|c|c|c|}
\hline & \multirow[b]{2}{*}{ No. of taxa } & \multicolumn{2}{|l|}{ Axis 1} & \multicolumn{2}{|l|}{ Axis 2} & \multirow{2}{*}{$\begin{array}{l}\text { Explained } \\
\text { variance \% }\end{array}$} \\
\hline & & Eigenvalue & $\begin{array}{l}\text { Species environment } \\
\text { correlation }\end{array}$ & Eigenvalue & $\begin{array}{l}\text { Species environment } \\
\text { correlation }\end{array}$ & \\
\hline Invertebrates & 133 & 0.092 & 0.715 & 0.061 & 0.664 & 19 \\
\hline Fish & 40 & 0.425 & 0.794 & 0.324 & 0.696 & 26.5 \\
\hline Macrophytes & 233 & 0.576 & 0.882 & 0.522 & 0.856 & 43.0 \\
\hline
\end{tabular}

dispersal relative to the habitat characteristics of each community (Table 6). Variables G2VU, LCBW, H1LUMN, and G1MBFC were common to all organism groups and included descriptors ranging from natural characteristics to physical transformations. None of the studied communities were strictly associated with a specific group of habitat attributes. On the contrary, a wide range of types of environmental variables were associated with each organism group, ranging from instream features to bankside and river corridor land use features. This array of descriptors, covering distinct features and spatial levels, is perhaps the most telling result taken from this study, namely that the three organism groups are influenced by a complex array of factors ranging from instream microhabitat descriptors to natural characteristics and human modifications occurring along the river corridor.

\section{Discussion}

The spatial variation of RHS parameters illustrates how difficult it is to develop habitat assessment techniques that can be considered valid for the survey 


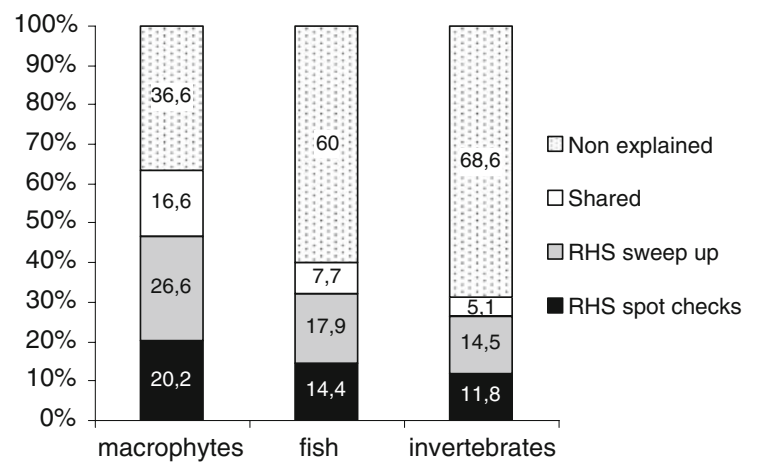

Fig. 1 Partial CCA results indicating the relative contribution of the RHS variables (instream spot checks and river corridor sweep-up) to each invertebrate, fish, and macrophyte communities

Table 6 Dissimilarity-based multivariate multiple regression (Bray-Curtis, DistLM) of selected RHS and hydraulic variables, ranked in order of contribution to the structure of each organism group

\begin{tabular}{lll}
\hline Macrophytes & Fish & Invertebrates \\
\hline G2VU & JTREES & JTREES \\
LCBW & G1FT & LCBW \\
H1LUMN & G1BMSD & G1BM \\
G1BMSD & LCBW & G2VU \\
G3Alg & G1MBFC & G1FT \\
G3Hyd & H2LMGR & KEFT \\
G1MBFC & V (max-min) & OIR \\
H1Grass & MMC & H1LUMO \\
& KEFT & G1CSSD \\
& OIR & ENR \\
& H1LUMO & H1LUSH \\
& ENR & G1CSM \\
& G1CFBR & IBPVS \\
& H1LUSH & LLP \\
& G2VU & G1MBFC \\
& LBH & G3Hyd \\
& & G1GE \\
& & H2LUMH \\
& &
\end{tabular}

of large geographical areas and for establishing environmental-biotic links. Results from MDA and MANOVA analyses showed clear geographical variation of habitat characteristics, in particular between principal catchments. These large-scale patterns, related to catchments and river type, concur with those of Johnson (1999) and Heino et al. (2002, 2005), where local environmental conditions were controlled by large-scale climatic, geological, and vegetation regimes. Results also showed that the WFD-based typology did not result in accurately segregated biological data. Dodkins et al. (2007) encountered similar difficulties in adjusting biological variation to differently derived typologies (WFD system A, multivariate analyses, and expert opinion) and went on to outline a technique that optimized boundaries for the different communities and the selection of environmental variables similar to the DistLM procedure used in this study. SánchezMontoya et al. (2007) showed that macroinvertebrate assemblage composition differed among three of four selected ecotypes and found significant differences between results from the bottom-up (from biological data) and top-down (from environmental data) classification approaches. These same aspects led Cortes et al. (2008) to establish biotic and abiotic linkages for individual catchments in order to elaborate specific indices. Of course, considering benthic fauna, we may also question whether a more detailed taxonomic resolution could not achieve a higher correspondence with the environmental variables.

Attempting to link physical factors with biological condition is one of the most fundamental challenges in developing habitat indices, a goal recognized by various authors (Armitage and Pardo 1995; Newson et al. 1998; Tickner et al. 2000). However, it is unrealistic to include all potential environmental parameters that are highly correlated with taxa or metrics and are sensitive to human impacts in a habitat survey. Multiple regression and pCCA results indicated that descriptors that are able to discriminate between disturbed and non-disturbed sites comprised lists of variables specific to each river type (Table 4), and that although various physical descriptors respond to stress (Table 6) many are meaningless when it comes to interpret the variations in composition and structure of aquatic fauna. Furthermore, each organism group is influenced by a complex array of different environmental parameters. Our findings amply illustrate how difficult it is to develop a "global habitat assessment method" capable of predicting and quantifying the magnitude of disturbance in across a range of organism groups. This constitutes an obvious drawback for the WFD, which advocates a standard or uniform hydromorphological assessment procedure.

Since biotic composition and ecosystem function result from a hierarchical interaction of multi-scale 
factors (Poff 1997; Frissel et al. 1986), hydromorphological characterization should logically include variables from different spatial scales. Multivariate analyses results highlight the importance of including different habitat scales (from the river channel to land use adjacent to the river) in order to fully represent the variability of the aquatic floral and faunal communities (Tables 3, 4, 5, 6). The specific responses of each organism group to different habitat descriptors and scales (Heino et al. 2005) indicate that links between lotic, biotic, and abiotic components are influenced by a complex range of factors. Even diversity patterns across local habitats have reported low-concordance in species richness for each organism group, with increasingly common patterns at biogeographical and regional scales (Flather et al. 1997; Heino et al. 2005). Collier (2008) found that land use appeared to be a key factor influencing benthic community composition among sites, whereas climate influenced stability and persistence within sites.

It is also necessary to be aware of other confounding effects on the interpretation of results such as sampling strategy, which also plays an important role and increases the complexity of interactions between biotic and abiotic variables. Results from Fig. 1 show that as biological inventories approach habitat survey scale (instream and river corridor), the ability to link biotic and abiotic data increases. However, it is important to stress that the organism groups are impaired as a result of both water quality and habitat degradation and additional work is necessary to effectively discriminate between the direct effects caused by eutrophication and toxic pollution from indirect physical habitat changes. Figure 1 illustrates that both instream and river corridor scale data were similarly important in characterizing the organism groups instead of the more traditional spatial hierarchy advocated by majority of the authors. Vondracek et al. (2005) reached the same conclusion when synthesizing different studies across scales, but when each study was analysed individually provided different relative contributions of the abiotic variables inside each scale.

River Habitat Survey is an appropriate technique for this purpose, since it considers two scales of analysis, instream point checks and river corridor sweep-up, at a given site. However, RHS does not reflect findings from instream habitat models that predict the effect of hydraulic habitat availability on aquatic communities. Instream flow incremental methodology (Bovee 1982), mainly used for defining fish flow requirements, uses the horizontal variation of simple parameters such as current velocity, depth, and habitat heterogeneity (shelter). In describing habitat for benthic macroinvertebrates, other key variables related to near-bed flow conditions such as bed shear stress (MobesHansen and Waringer 1998) and FST hemisphere numbers (Mérigoux and Dolédec 2004) have been shown to exhibit high predictive ability. Thus, it is not surprising that species diversity in streams has been related to geomorphic complexity and variability of hydraulic factors (Palmer et al. 1997). In this study, only the range of velocities and Froude number were both significantly related to anthropogenic stress (Table 3). However, the determination of these parameters was conducted only once, mainly during low-flow conditions. We believe that the measurement of the temporal variation of channel characteristics and flow resistance and continuity could provide a more significant relationship of the hydraulic or hydrologic parameters with the biota. These factors are also of great importance for establishing associations between flood events and sediment/nutrient transport, which in turn influence the distribution of finer scale hydraulic habitat conditions (Lamouroux 1998; Stewardson 2005). Such variables allow assessment of channel geometry dynamics and can be used to determine at which stage a given stream reach is in the process of channel form adjustment related to the processes of degradation and aggradation (Simon and Castro 2003). In fact, channel boundary is deformable in response to changes in discharge and sediment supply and will continually deform toward the most stable state (Wohl and Merrit 2007).

We conclude that RHS methodology lacks information on hydraulic geometry and propose the inclusion of several parameters, listed in Table 7, which provide essential information on morphometric and hydraulic variability linked with different aquatic communities' habitats. This list of parameters is merely an attempt to fill the present "gap" in habitat characterization; further validation is required including tests of their statistical independence. Measurement of these parameters is compatible with RHS field methodology, requiring only a minor supplementary effort in situ. Other studies (Zigler et al. 2008) suggest that habitat conditions during flood events such as shear-stress, rather than those at summer baseflow, better explain the abundance of particular benthic species such as mussels, since they 
Table 7 Hydraulic parameters to include in the habitat survey as a complement RHS forms

\begin{tabular}{lll}
\hline Hydraulic parameters & Method of measurement & Expressions \\
\hline Max-min depth & At each spot-check & \\
Max-min velocity & At each spot-check & \\
Mean max depth $\left(h_{\mathrm{m}}\right)^{\mathrm{a}}$ & At each spot-check & \\
Mean velocity $(U)$ & Selected cross-section & $\omega=\rho g Q S$ \\
Discharge $(Q)$ & Selected cross-section & $n=\left(n_{\mathrm{b}}+n_{1}+n_{2}+n_{3}+n_{4}\right) m$ \\
Stream power $(\omega)$ & Entire segment & $\tau g S^{1 / 4} \mathrm{Ks}^{-3 / 2} U^{3 / 2}$ \\
Manning coefficient of roughness $(n)$ & Entire segment & $U /\left(g h_{\mathrm{m}}\right)^{0.5}$ \\
Shear stress & Selected cross-section & $U h_{\mathrm{m}} / v$ \\
Froude number $($ Fr) & Selected cross-section & $\mathrm{RBS}=U_{\mathrm{CR}} / U_{\mathrm{B}} ; U_{\mathrm{CR}}=0.155\left(D_{50}\right)^{0.5}$ \\
Reynolds number $($ Re) & Selected cross-section & \\
River bed stability index $(\mathrm{RBS})$ & Selected cross-section & \\
\hline Coefficient of variation & From data in the 10 spot-checks & \\
\hline Width & 1 m from the bank & \\
Velocity & 1 m from the bank & \\
Depth & & \\
Ratio $w / h_{\mathrm{m}}$ & & \\
\hline Data collection is & & \\
\hline
\end{tabular}

Data collection is simplified and takes into account RHS design in order to reduce measurement time in the field. Formulae are illustrative, i.e., the same variables can be obtained by other formulae

$U$, mean velocity in the selected cross-section $(\mathrm{m}) ; h_{\mathrm{m}}$, mean depth $(\mathrm{m})$ in the selected cross-section; $v$, kinematic viscosity $\left(\mathrm{m}^{2} / \mathrm{s}\right) ; \rho$, water specific weight $\left(\mathrm{kg} / \mathrm{m}^{3}\right) ; g$, gravitational constant $(\mathrm{m} / \mathrm{s}) ; Q$, flow $\left(\mathrm{m}^{3} / \mathrm{s}\right) ; n_{\mathrm{b}}$, Manning coefficient for a straight channel of natural materials; $n_{1}$, correction for superficial irregularities: $n_{2}$, correction for section variations; $n_{3}$, correction for obstructions; $n_{4}$, correction for aquatic vegetation; $m$, correction for meandering; Ks, coefficient Manning-Strickler $=1 / n ; U_{\mathrm{B}}$, near-bed velocity $(\mathrm{m} / \mathrm{s})$; $D_{50}$, diameter of mean bed materials $(\mathrm{mm})$

a From data collected $1 \mathrm{~m}$ from the bank

depend on "hydraulic refugia", namely areas of the stream bed that remain stable following spate episodes. There are obvious problems in field collection of data during extreme events, which can instead be derived through modeling.

Physical habitat quality assessment in wadeable streams, which are generally of medium to high gradient, uses metrics that are ineffective in large rivers, resulting in poor scores. A requirement of the WFD is also assessment of lateral connectivity. However, since lowland streams are virtually absent in Portugal, this association was not considered. Wilhelm et al. (2005) created a specific index for non-wadeable streams, including metrics such as offchannel habitats, bottom deposition, and abundance of large woody debris. We suggest that it may be desirable to expand RHS-modified metrics to characterize backwaters, off-channel variation, tributaries, and island habitats, which exhibit extreme variation in large floodplains rivers (Kellerhals and Church 1989).
In conclusion, we emphasize the need to develop habitat assessment strategies that integrate different complementary spatial scales in order to effectively describe the major proportion of the regional variability in lotic diversity (e.g., at catchment level). Such strategies must include information ranging from microhabitat level (that includes local hydraulic characterization) to the assessment of river corridor condition and surrounding land use. Global habitat condition assessment methods, such as the case of the WFD, should be based on physical inventories that support the spatial scale of the biological surveys and include a complete set of parameters that encompass the habitat descriptors responsible for the structure of each organism group. Finally, river typology definition and respective ecological classification must be based upon acceptable levels of concordance between biological and environmental data. It was possible to observe that habitat parameters could be linked to the typological division of system $\mathrm{B}$ as well as 
catchments. But do different biotic assemblages correspond to this imposed artificial discrimination? This is a key consideration for ensuring the effective definition of reference conditions for each river type and the WFD must assure that such artificial division of river types, based on obligatory and facultative abiotic factors, corresponds to more or less similar patterns within aquatic organism groups. This "biological validation" of river types will require further attention.

Acknowledgment This work was provided by the project PPCDT/AMB/56424/04 sponsored by Portugal Foundation for Science and Technology.

\section{References}

Amoros C (2001) The concept of habitat diversity between and within ecosystems applied to river side-arm restoration. Environ Manag 28(6):805-817. doi:10.1007/s0026700 10263

Anderson MJ, Gorley RN (2007) Experimental design and analysis of multivariate ecological data. Lecture notes. PRIMER-E Ltd, UK. Univ Evora Portugal 17-21 (September)

Armitage PD, Pardo I (1995) Impact assessment of regulation at the reach level using macroinvertebrate information from mesohabitats. Regul Rivers Res Manag 10:147-158. doi:10.1002/rrr.3450100210

Bovee KD (1982) A guide of stream habitat analysis using the instream flow incremental methodology. U.S. Fish and Wildlife Service FWS/OBS 82/26, pp 248

Brierley GJ, Fryirs K (2000) River styles in Bega Catchment, NSW, Australia: implications for river rehabilitation. Environ Manag 25(6):661-679. doi:10.1007/s0026700 10052

Collier KJ (2008) Temporal patterns in the stability, persistence and condition of stream macroinvertebrate communities: relationships with catchment land-use and regional climate. Freshw Biol 53:603-616. doi:10.1111/ j.1365-2427.2007.01923.x

Cortes RMV, Oliveira SV, Hughes SJ, Ferreira MT (2008) Combining habitat and biological characterization: ecological validation of the River Habitat Survey. Limnetica 27(1):39-56

Dodkins I, Rippey B, Harrington TJ, Bradley C, Chatain BN, Kelly-Quinn M, McGarrigle M, Hodge S, Dolédec S, Lamouroux N, Fuchs U, Mérigoux S (2007) Modelling the hydraulic preferences of benthic macroinvertebrates in small European streams. Freshw Biol 52:145-164. doi: 10.1111/j.1365-2427.2006.01663.x

FAME Consortium (2004) Manual for the application of the European fish index-EFI. A fish-based method to assess the ecological status of European rivers in support of the Water Framework Directive. Version 1.1. http://fame. boku.ac.at. Accessed 25 Apr 2004
Flather CH, Wilson KR, Dean JD, McComb WC (1997) Identifying gaps in conservation networks: of indicators and uncertainty in geographic-based analysis. Ecol Appl 7:531-542. doi:10.1890/1051-0761(1997)007[0531: IGICNO]2.0.CO;2

Frappier E (2007) A new index of habitat alteration and a comparison of approaches to predict stream habitat conditions. Freshw Biol 52:2009-2020. doi:10.1111/j.13652427.2007.01803.x

Frissel CA, Liss WJ, Warren CE, Hurley MD (1986) A hierarchical framework for stream habitat classification. Environ Manag 10:199-214. doi:10.1007/BF01867358

Gergel SE, Turner MG, Miller JR, Melack JM, Stanley EH (2002) Landscape indicators of human impacts to riverine systems. Aquat Sci 64:118-128. doi:10.1007/s00027-0028060-2

Heino J, Muotka T, Paavola R, Hamalainen H, Kpskenniemi E (2002) Correspondence between regional delineations and spatial patterns in macroinvertebrate assemblages of boareal headwater streams. J N Am Benthol Soc 21:397413. doi: $10.2307 / 1468478$

Heino J, Muotka T, Paavola R (2003) Determinants of macroinvertebrate diversity in headwater streams: regional and local influences. J Anim Ecol 72:425-434. doi: 10.1046/j.1365-2656.2003.00711.x

Heino J, Paavola R, Virtainen R, Muotka T (2005) Searching for diversity indicators in running waters: do bryophytes, macroinvertebrates and fish show congruent diversity patterns? Biodivers Conserv 14:415-428

Hughes SJ, Ferreira MT, Cortes RMV (2008) Hierarchical spatial patterns and drivers of change in benthic macroinvertebrate communities in an intermittent Mediterranean river. Aquat Conserv: Mar Freshw Ecosyst 18:742-760. doi:10.1002/aqc.866

INAG (2008) Characterization of river types in Portugal according to the implementation of the Water Framework Directive (in Portuguese). Ministério do Ambiente, do Ordenamento do Território e do Desenvolvimento Regional, Lisboa, p 31

Jackson DA, Peres-Neto PR, Olden JD (2001) What controls who is where in freshwater fish communities - the roles of biotic, abiotic and spatial factors. Can J Fish Aquat Sci 58:157-170. doi:10.1139/cjfas-58-1-157

Jaworski A (1993) The application of the ecotone concept in defining nutrient management requirements for the upper Potomac River basin. Hydrobiologia 251:341-349. doi: 10.1007/BF00007193

Johnson RK (1999) Regional representativeness of Swedish reference lakes. Environ Manag 23:113-124. doi:10.1007/ s002679900172

Kellerhals R, Church M (1989) The morphology of large rivers: characterization and management In: Dodge DP (ed) Proceedings of the international Large River symposium, Publications of Fisheries and Aquatic Science, Ottawa, pp 31-49

Lamouroux N (1998) Depth probability distributions in stream reaches. J Hydraul Eng 124:224-228. doi:10.1061/ (ASCE)0733-9429(1998)124:2(224)

Lamouroux N, Oliviers JM, Persat H, Pouilly M, Sochon Y, Statzner B (1999) Predicting community characteristics from habitat conditions: fluvial fish and hydraulics. 
Freshw Biol 42:275-299. doi:10.1046/j.1365-2427.1999. 444498.x

Logan P, Furse M (2002) Preparing for the European Water Framework Directive-making the links between habitat and aquatic biota. Aquat Conserv: Mar Freshw Ecosyst 12:425-437. doi:10.1002/aqc.535

McCune B, Grace JB (2002) Analysis of ecological communities. MJM Software Design, Oregon, p 302

Mérigoux S, Dolédec S (2004) Hydraulic requirements of stream communities: a case study on invertebrates. Freshw Biol 49:600-613. doi:10.1111/j.1365-2427. 2004.01214.x

Mesquita N, Coelho MM, Filomena MM (2006) Spatial variation in fish assemblages across small Mediterranean drainages: effects of habitat and landscape context. Environ Biol Fish 77:105-120. doi:10.1007/s10641006-9058-8

Mobes-Hansen B, Waringer JA (1998) The influence of hydraulic stress on microdistribution patterns of zoobenthos in a sandstone brook. Int Rev Hydrobiol 83:381-396. doi:10.1002/iroh.19980830506

Naiman RJ (ed) (1992) Watershed management: balancing sustainability and environmental change. Springer-Verlag, New York

Newson MD, Harper DM, Padmore CL, Kemp JL, Vogel B (1998) A cost-effective approach for linking habitats, flow types and species requirements. Aquat Conserv: Mar Freshw Ecosyst 8:431-446. doi:10.1002/(SICI)10990755(199807/08)8:4<431::AID-AQC302>3.0.CO;2-W

Oberdoff T, Hugueny B, Compin A, Belkessam D (1998) Noninteractive fish communities in the coastal streams of north-western France. J Anim Ecol 67:472-484. doi: 10.1046/j.1365-2656.1998.00211.x

Oliveira SV, Cortes RMV (2005) A biologically relevant habitat condition index for streams in northern Portugal. Aquat Conserv: Mar Freshw Ecosyst 15:189-210. doi: 10.1002/aqc.671

Palmer MA, Hakenkamp CC, Nelson-Baker K (1997) Ecological heterogeneity in streams: why variance matters. J N Am Benthol Soc 161:189-202. doi:10.2307/1468251

Poff NL (1997) Landscape filters and species traits: towards mechanistic understanding and prediction in stream ecology. J N Am Benthol Soc 16:391-409. doi:10.2307/ 1468026

Raven PJ, Fox P, Everard M, Holmes NTH, Dawson FH (1997) River Habitat Survey: a new system for classifying rivers according to their habitat quality. In: Boo PJ, Howell DL (eds) Freshwater quality: defining the indefinable?. The Stationery Office, Edinburg, pp 215-234

Raven PJ, Holmes NTH, Dawson FH, Fox PJA, Everard M, Fozzard IR, Rouen KJ (1998) River habitat quality: the physical character of rivers and streams in the UK and the Isle of Man. River Habitat Survey report no. 2, Environment Agency, Bristol

REFCOND (2003) Guidance on establishing reference conditions and ecological status class boundaries for inland surface waters. CIS Working Group 2.3. Final Version 7.0
Roth NE, Allan JD, Erickson DL (1996) Landscape influences on stream biotic integrity assessed at multiple spatial scales. Landscape Ecol 11:141-156. doi:10.1007/ BF02447513

Sánchez-Montoya MDEL, Puntí T, Suárez ML, Vidal-Abarca MDEL, Rieradevall M, Poquet JM, Zamora-Muñoz C, Robles S, Álvarez M, Alba-Tercedor J, Toro M, Pujante AM, Munne A, Prat N (2007) Concordance between ecotypes and macroinvertebrate assemblages in Mediterranean streams. Freshw Biol 52:2240-2255. doi:10.1111/ j.1365-2427.2007.01826.x

Shurin JB, Havel JE, Leibold MA, Pinel-Alloul B (2000) Local and regional zooplankton species richness: a scale-independent test for saturation. Ecology 81:3062-3073

Simon A, Castro J (2003) Measurement and analysis of alluvial channel form. In: Kondolf GM, Piégay H (eds) Tools in fluvial geomorphology. Wiley, Chichester, pp 291-322

Statsoft Inc. (2004) Statistica (DATA analysis software system). Version 7, Tulsa

Stevens RD, Wilig MR (2002) Geographical ecology at the community level: perspectives on the diversity of the new world bats. Ecology 83:545-560

Stewardson M (2005) Hydraulic geometry of stream reaches. J Hydrol (Amsterdam) 306:97-111. doi:10.1016/j.jhydrol. 2004.09.004

ter Braak CJF, Smilauer P (2002) CANOCO reference manual and CanoDraw for Windows user's guide: software for canonical community ordination (version 4.5). Microcomputer Power, Ithaca

Tickner D, Aritage PD, Bickerton MA, Hall KA (2000) Assessing stream quality using information on mesohabitat distribution and character. Aquat Conserv: Mar Freshw Ecosyst 10:179-186. doi:10.1002/1099-0755(200005/06) 10:3<179::AID-AQC403>3.0.CO;2-U

Tonn WM, Magnuson JJ, Rask M, Toivonen J (1990) Intercontinental comparison of small-lake fish assemblages: the balance between local and regional processes. Am Nat 136:345-375. doi:10.1086/285102

Vondracek B, Blann KL, Cox CB, Nerbonne JL, Mumford KG, Nerbonne BA (2005) Land use, spatial scale and stream systems: lessons from an agricultural region. Environ Manag 36:775-791. doi:10.1007/s00267-005-0039-z

Wilhelm JGO, Wessel KJ, Merrit RW, Cummins KW (2005) Habitat assessment of non-wadeable rivers in Michigan. Environ Manag 36:592-609. doi:10.1007/s00267-0040141-7

Wohl E, Merrit DM (2007) Reach-scale channel geometry of mountain streams. Geomorphology 93(3-4):168-185. doi: 10.1016/j.geomorph.2007.02.014

Zigler SJ, Newton TJ, Steuer JJ, Bartsch MR, Sauer JS (2008) Importance of physical and hydraulic characteristics to unionid mussels: a retrospective analysis in a reach of large river. Hydrobiologia 598:343-360. doi:10.1007/ s10750-007-9167-1 